\title{
Do jogo ao espetáculo: a midiatização do streaming de games na plataforma Twitch
}

From game to spectacle: the mediatization of streaming games on Twitch platform

Renata Jéssica Galdino ${ }^{a}$

ORCID: http://orcid.org/0000-0003-3111-2737

Tarcisio Torres Silva ${ }^{b}$

ORCID: http://orcid.org/0000-0001-9347-7585

Carlos Alberto Zanottic

ORCID: http://orcid.org/0000-0002-6644-7206

Recebido em: 11/11/2020. Aprovado em: 26/04/2021.

\section{Resumo}

Este trabalho analisa a plataforma de streaming Twitch a partir da perspectiva da midiatização, um processo que concebe o fenômeno de novos padrões de interação promovidos pelas mídias em sua relação com a sociedade. Compreendemos que a plataforma leva os usuários a novas experiências no mundo dos games, promovendo interferências na relação original, como o ato de assistir, narrar ou se inserir como figura influente, permitindo o advento de novas celebridades na sociedade do espetáculo.

Palavras-chave: Games. Midiatização. Twitch.

\begin{abstract}
This work analyzes the Twitch streaming platform from the perspective of mediatization, a process that conceives the phenomenon of new interaction patterns promoted by the media in their relationship with society. It is understood that the platform brings new experiences to user in the world of games, promoting interference in the original relation, such as watching, narrating or entering yourself as an influential figure, allowing the arising of new celebrities in the society of the spectacle.
\end{abstract}

Keywords: Games. Mediatization. Twitch.

\section{Introdução}

A popularidade dos games não é necessariamente algo novo na indústria do entretenimento, uma vez que consoles estão presentes em boa parte dos lares desde os anos 80 do século passado. O notável é que, na última década, essa mídia vem passando por um verdadeiro processo de espetacularização, o que pode ser relacionado à popularização do streaming de games. Enquanto mídia, os games não se prestam exclusivamente ao ato de jogar,

\footnotetext{
${ }^{a}$ Pontifícia Universidade Católica de Campinas (PUC). Campinas/Brasil. E-mail: rejgaldino@gmail.com

${ }^{b}$ Pontifícia Universidade Católica de Campinas (PUC). Campinas/Brasil. E-mail: tartorres@gmail.com

${ }^{c}$ Pontifícia Universidade Católica de Campinas (PUC). Campinas/Brasil. E-mail: carlos.a.zanotti@gmail.com
} 
podendo ser descritos como um fenômeno sociocultural que envolve questões socioeconômicas, de produção cultural, de comunicação e interação social (SANTAELLA, 2013).

Inseridos em uma sociedade que vem passando por transformações pautadas pelo avanço tecnológico e pela massificação das mídias digitais, os games reúnem potencial para alterar a arquitetura social e concorrem para ajudar a moldar a maneira como as pessoas se comportam e se relacionam. A partir deste cenário, surge a pergunta central que este trabalho busca responder: o que motiva o fenômeno das transmissões de jogos digitais via streaming e quais suas consequências para o contexto cultural do qual fazem parte?

Propomos, neste artigo, por meio do estudo da literatura especializada e pesquisas documental e observacional, analisar o fenômeno da midiatização e da espetacularização do streaming de games na plataforma Twitch ${ }^{1}$, empresa líder neste ramo da indústria de entretenimento. De natureza exploratória, esse trabalho busca compreender de que forma a midiatização tem impactado o processo de produção e consumo dos espetáculos transmitidos pelos streamers de jogos online.

Para tanto, propomos adotar intersecções entre os estudos da midiatização (HJARVARD, 2014; DALL'AGNES; BARRICHELLO, 2018) e da sociedade do espetáculo (DEBORD, 2003; SILVA; TAVARES, 2013) como aporte teórico-epistemológico. O caráter exploratório deste estudo faz uso da pesquisa descritiva como percurso possível para abarcar a complexidade do diálogo pretendido.

Partimos da perspectiva da midiatização, que se concentra nas transformações estruturais de longo prazo das relações entre mídia, cultura e sociedade, sob a ótica do pesquisador dinamarquês Stig Hjarvard. E buscamos seus antecedentes no conceito de "sociedade do espetáculo" desenvolvido nos anos 60 por Guy Debord.

Entendemos que as características da espetacularização a que se referia o ideólogo marxista francês vão ao encontro da perspectiva da midiatização tal como observada em Hjarvard, 2014, permitindo-nos compreender que mídia e sociedade são organizadas, na sociedade regida pela lógica da mercadoria, em torno da produção e consumo de imagens, objetos e eventos culturais. Para o pensador francês, o espetáculo "unifica e explica uma grande diversidade de fenômenos aparentes" (DEBORD, 2003, p. 16).

\footnotetext{
${ }^{1}$ twitch.tv
} 
Entre eles, a imagem do sujeito que, tomado por este sistema de valores, busca fazer-se ver, utilizando-se para isso das possibilidades criadas pelo desenvolvimento tecnológico (KARHAWI, 2017).

Esse viés de análise parece acolher a complexidade das transmissões via streaming de jogos digitais que concentram camadas da estratégia que o ideólogo marxista chamou de "fazer ver", uma vez que a ação realizada em jogo existe apenas no espectro da imagem. São simulações de ações que se dão exclusivamente no ciberespaço e que são distribuídas, consumidas e apropriadas por outros indivíduos por meio das plataformas de transmissão de vídeo. Para que seja possível compreender essas novas configurações da experiência de competir, produzir e compartilhar conteúdo, é importante que se obtenha um panorama do cenário atual da indústria gamer e o papel das transmissões via streaming.

\section{A indústria gamer}

O tamanho do mercado e a popularidade dos jogos digitais podem ser dimensionados a partir de um simples dado inicial: mais de 2,5 bilhões de pessoas, ou 32\% da população mundial, pode ser considerada gamer. Sem uma definição específica para o termo, diversos autores (MCGONIGAL, 2017; ZICHERMANN; CUNNINGHAM, 2011), pesquisadores da área (CASSELL; JENKINS, 1998; GOULAR; NARDI, 2017; KOWAL et al., 2018; PAAßEN; MORGENROTH; STRATEMEYER, 2017) e profissionais da indústria (NEWZOO, 2018; PESQUISA, 2019) adotam diferentes métricas para descrever as características de um gamer.

Neste trabalho, optamos pela definição utilizada na Pesquisa Gamer Brasil, realizada em 2019 (PGB, 2019), que considera gamer qualquer pessoa habituada a participar de jogos digitais, independentemente do tipo de jogo, frequência, duração das partidas, profissionalização ou conhecimento sobre jogos, softwares e hardwares relacionados (PESQUISA, 2019). Ao redor do mundo, o contingente de pessoas que se enquadram nesta descrição sustenta uma indústria que já é $40 \%$ maior que a indústria cinematográfica e sete vezes maior que a indústria fonográfica, conforme se observa na Figura 1, a seguir. 
Figura 1- Lucro global em 2018 das indústrias gamer, cinematográfica e fonográfica em US\$ bilhões

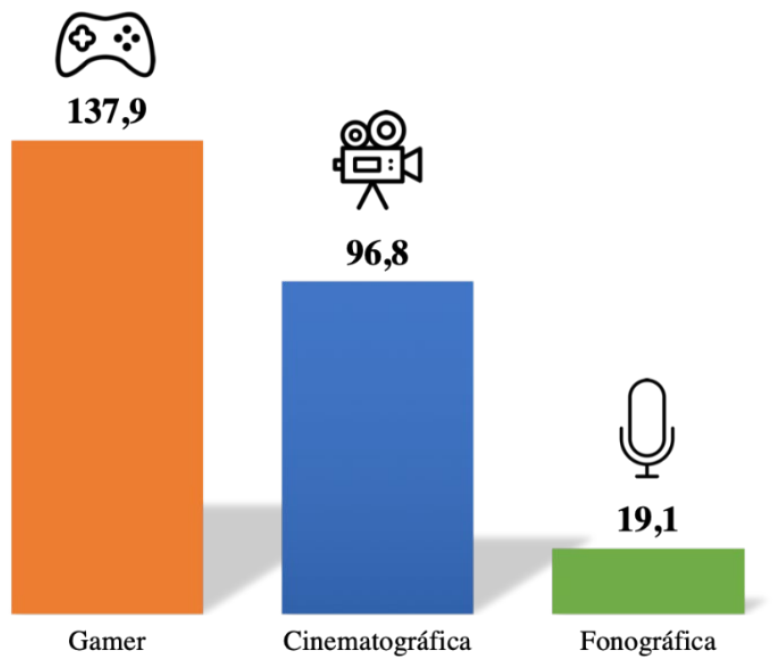

Fonte: Os autores, com dados do IFPI Global Music Report $2019^{2}$

Analistas do setor estimaram que, em 2019, a indústria gamer movimentou um volume aproximado a US\$ 152,1 bilhões, com crescimento de 9,6\% em relação ao ano anterior. A projeção para o mercado global de games é de que os gastos dos consumidores com jogos crescerão para US\$ 196 bilhões até 2022 (NEWZOO, 2019a).

Entre os segmentos que mais se destacam no setor estão os jogos de consoles, que registraram um crescimento de vendas de 13,4\% em 2018 e foram responsáveis por gerar movimentação de US\$ 47,9 bilhões em 2019. O segmento de consoles é seguido pelos jogos para dispositivos móveis (smartphone e tablet), que crescem 10,2\% ao ano e já respondem por uma fatia de $45 \%$ do mercado global de jogos (NEWZOO, 2019a).

Segundo a TIC Domicílios 2018, entre os 77\% dos brasileiros que já utilizaram a internet, 35\% afirmam ter jogado online nos últimos 3 meses (TIC, 2019). A plataforma mais utilizada é o smartphone, respondendo por $83 \%$ do acesso dos gamers brasileiros, seguido pelos consoles com, 48,5\%, e notebooks, com 42,6\% (PESQUISA, 2019). Quanto ao gênero do usuário, o feminino corresponde a $53 \%$ do público, sendo a maioria considerada jogadoras "casuais", ou seja, participam com frequência, em sua maioria por meio de smartphones, preferindo jogos gratuitos. Entre os gamers considerados "hardcore", o gênero masculino é maioria, representando 58,9\% deste segmento. Esse público joga com muita frequência partidas de longa duração, conhece muitos títulos de jogos, gosta de jogar em smartphone, consoles e PCs e investe regularmente na compra de games (PESQUISA, 2019).

\footnotetext{
2 Informações obtidas a partir de dados divulgados pela IFPI Global Music Report 2019; Newzoo, 2018; The Motion Picture Association of America, Inc. (MPAA), 2019.
} 
O Brasil ocupa a segunda posição na América Latina em receita de games. Segundo as análises, em 2019 esse mercado movimentou cerca de US\$ 1,6 bilhão no país, ficando atrás apenas do México, que gerou US\$ 1,8 bilhão em receita (NEWZOO, 2019a).

Entre os gamers brasileiros, as mulheres representam 53\% do público, sendo maioria pelo quarto ano consecutivo. Quanto à idade, os adeptos dos games se concentram na faixa entre 25 e 54 anos, contrariando o senso comum de que jogos digitais são atividade exclusiva dos adolescentes. As plataformas preferidas por eles são o smartphone (83\%) e consoles de videogame $(48,5 \%)$.

O universo dos games engloba uma ampla ramificação de categorias e atividades, como as comunidades de jogadores, empresas produtoras, instituições de ensino voltadas ao desenvolvimento de profissionais da área, mídia especializada e outras. Entre elas, os chamados eSports ganharam destaque especial nos últimos anos. O Brasil é líder em audiência de eSports na América Latina. Mais de 9 milhões de brasileiros assistem a torneios de eSports mais de uma vez por mês, podendo ser classificados como entusiastas da categoria (NEWZOO, 2019b). Mais de $60 \%$ dos brasileiros conhecem ou já ouviram falar de eSports; destes, $48 \%$ praticam e 12,9\% ainda não, mas pretendem praticá-los algum dia. Entre os entusiastas dos eSports, 69\% são homens e 31\%, mulheres, com a maior concentração na faixa etária entre 21 e 35 anos. Os dados apontam que 69\% dos fãs de eSport consomem conteúdo relacionado ao tema pelo menos uma vez por semana (PESQUISA, 2019). Os fãs brasileiros são conhecidos por sua paixão e dedicação aos jogos, equipes e eventos.

\section{O streaming de games}

Em termos técnicos gerais, o streaming é uma forma de transferência de dados que podem ser de áudio e/ou vídeo através da internet, ao vivo (live broadcasting/webcasting) ou em transmissão gravada (on demand) (OLIVEIRA et al., 2017). O avanço da tecnologia e a popularização da internet de banda larga vivenciados nos últimos anos possibilitaram uma rápida expansão de conteúdos via streaming. Segundo o relatório anual Visual Networking Index (VNI), o consumo de serviços de streaming de vídeo poderá alcançar $82 \%$ do tráfego de dados da internet já em 2021 (CISCO, 2018).

No contexto dos games, o streaming diz respeito a transmissões ao vivo de conteúdo audiovisual relacionado a jogos eletrônicos por meio de plataforma digitais que, além de transmitir o conteúdo, permitem a interação entre os streamers - usuários que transmitem sessões de jogos - e os viewers - aqueles que assistem às partidas. 
Dados de 2017 apontam que os games são responsáveis por 60\% do fluxo de audiência de streaming, superando serviços consagrados como Netflix, HBO GO, Deezer e Spotify (GAMING, 2017). Projeções apontam que o tráfego de dados na internet relacionado aos jogos e ao streaming de jogos irá crescer nove vezes entre 2017 e 2022 (CISCO, 2018).

Quanto à configuração das transmissões, em geral o game ou conteúdo a ser apresentado ocupa o maior espaço da tela, sobreposto por uma janela menor que focaliza a imagem do streamer, conforme a Figura 2, a seguir:

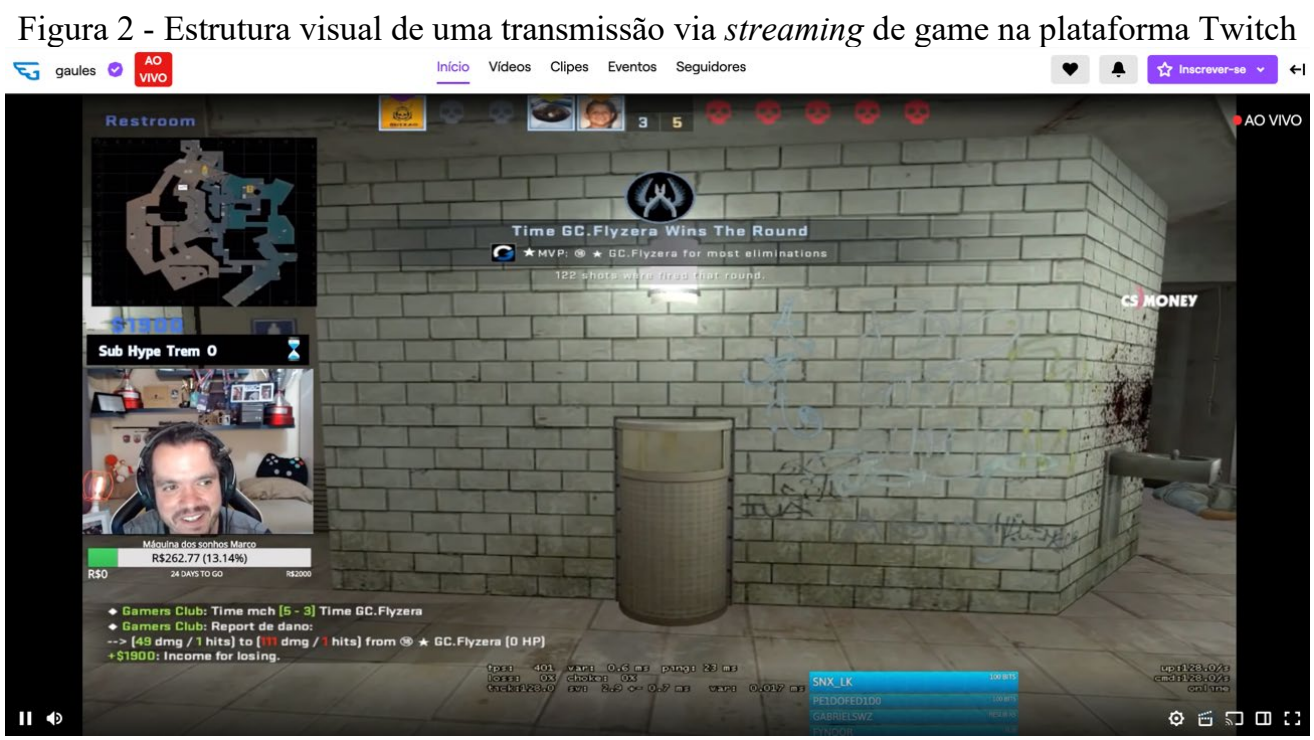

Fonte: Print da tela Twitch - gaules, 2019

Na Figura 2, o streamer Gaules ${ }^{3}$ realiza a transmissão de uma partida multiplayer do jogo Counter-Strike: Global Offensive ${ }^{4}$ por meio da plataforma Twitch. O game é apresentado em destaque, ocupando a maior parte da tela, sendo sobreposto no canto inferior esquerdo pela janela que exibe o rosto do streamer, de forma que suas reações e expressões possam ser acompanhadas durante toda a partida.

Em geral, nas transmissões é utilizado enquadramento do plano close, destacando a face do streamer, mas ainda assim permitindo um breve vislumbre do local onde o jogador se instala. $\mathrm{Na}$ imagem em questão, nota-se que a transmissão é feita a partir de um local que aparenta ser o quarto do jogador. É possível ver parte de sua decoração, com troféus, fotos, almofadas e uma cama, configurando uma relação de informalidade e extrema intimidade entre o streamer e sua

\footnotetext{
${ }^{3}$ Nickname ou apelido de Alexandre Gaules, primeiro streamer brasileiro a alcançar marca de dez mil subscritos na Twitch e atualmente o streamer de língua portuguesa mais popular da plataforma (NEWZOO, 2019b).

${ }^{4}$ Counter-Strike: Global Offensive (CS:GO) é um jogo online desenvolvido pela Valve Corporation e pela Hidden Path Entertainment, o título está entre os cinco primeiros do ranking de jogos para PC mais populares nos últimos dois anos (NEWZOO, 2018).
} 
audiência. De forma sistemática, observa-se que este tipo de cenário é utilizado pela maioria dos streamers.

Usualmente, o áudio do jogo é transmitido em baixo volume, de forma a não atrapalhar o som do microfone do streamer, usado para ele se comunicar com os demais jogadores e viewers, e para comentar sua própria performance durante toda a partida. Essa sobreposição de microfone e webcam permite que o streamer compartilhe informações sobre o jogo, bem como opine sobre a atividade de jogar ou relativa a qualquer outro tema, levando-o ao papel de líder na comunidade, o que reforça sua influência sobre os espectadores (SJÖBLOM et al., 2019).

Diferentes empresas oferecem serviços de streaming voltados especificamente ao público gamer, destacando-se entre elas, por quantidade de usuários ativos, Twitch (Amazon); Youtube Gaming (Google); Mixer (Microsoft); Facebook Gaming (Facebook); Periscope (Twitter). Vale registrar que as plataformas tratam-se de subsidiárias de grandes empresas do ramo de tecnologia que buscam expandir sua penetração de mercado entre o público gamer.

A Twitch lidera em penetração de mercado, tendo atingido a marca de 27 mil streamers simultâneos em 2017, o que correspondeu a um crescimento de 197\% em apenas um ano. O Youtube Gaming, que aparece na segunda posição em quantidade de streamers, apresentou um crescimento ainda maior, de $343 \%$ no ano de 2017, alcançando a marca de 7 mil streamers simultâneos (HICKS, 2018). A Figura 3, a seguir, ilustra as quantidades de streamers ativos no último trimestre de 2018 por plataforma.

Figura 3 - Streamers Ativos por Plataforma (Out, Nov e Dez de 2018)

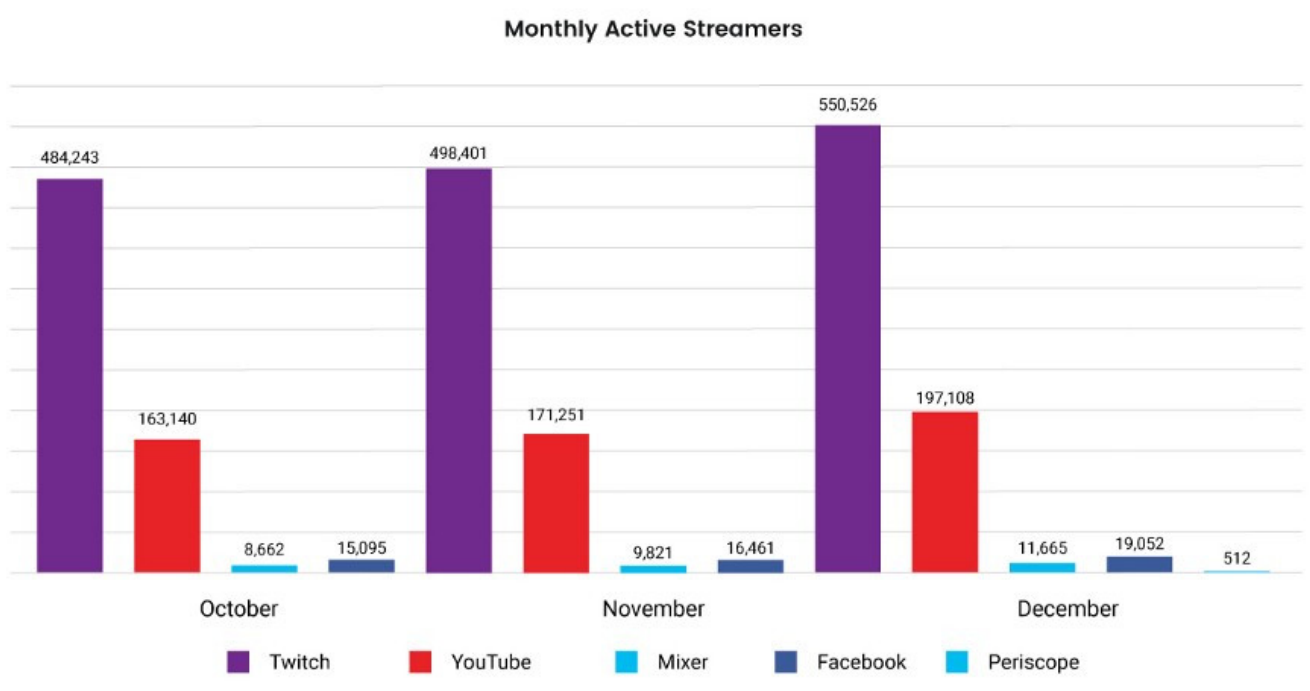

Fonte: Hicks, 2018 
A Twitch se define como "Social video for gamers", em tradução livre "Rede social de vídeo para gamers". Trata-se de uma plataforma social de distribuição de vídeos na qual cerca de 9,7 milhões de usuários assistem diariamente a partidas de jogos online e interagem com mais de 2 milhões de streamers de todas as partes do mundo. Fundada em 2011, a empresa nasceu como uma extensão da JustinTV, uma plataforma na qual Justin Kan, fundador do serviço, transmitia sua vida online por meio de uma câmera acoplada na cabeça. A JustinTV encerrou suas operações em 2014, ano em que a Twitch foi adquirida pela Amazon por US\$ 970 milhões. Por meio da plataforma, os usuários podem transmitir jogos ao vivo utilizando computadores e consoles como o Playstation e Xbox (AMAZON, 2014).

Quanto ao modelo de negócio, a principal fonte de receitas da Twitch são grandes anunciantes, em especial empresas voltadas ao universo gamer, como desenvolvedoras de jogos, fabricantes de consoles e de dispositivos (computadores, mouses, fones de ouvido, etc.). $\mathrm{O}$ acesso à plataforma é gratuito, sendo também oferecidos serviços premium aos usuários, por valores que oscilam entre US\$ 4,99 e US\$ 24,99 dólares mensais, que possibilitam desde uma experiência de navegação sem anúncios a conteúdos exclusivos, e até o acesso a séries e músicas do catálogo da Amazon.

A Twitch recompensa seus streamers por meio dos programas "afiliados" e "parceiros". No programa "afiliados", os streamers podem receber receitas a partir de Bits, espécie de mercadoria virtual que pode ser convertida em dinheiro, bem como por meio das vendas de jogos e de artigos de jogos em seus canais. No programa "parceiros", os streamers têm as mesmas possibilidades dos "afiliados", porém com maior quantidade e variedade de benefícios, além da possibilidade de remuneração por anúncios em seus vídeos (JUNTANDO, 2018). Os ganhos podem variar entre US\$ 0,02 e US\$2,00 para cada mil visualizações de anúncios. Como plataforma, se destaca por sua abordagem inovadora no formato de monetização que, embora seja semelhante à realizada por outros serviços, como o YouTube, por exemplo, ampliou a perspectiva de ganhos tangíveis e o engajamento de seus streamers por meio de processos de gamificação (SJÖBLOM et al., 2019).

A empresa oferece também o Twitch Student, programa que tem como pilares a "Inclusão, Diversidade e Colaboração", com o objetivo de impulsionar jovens estudantes a se desenvolverem como profissionais na indústria dos games (JUNTANDO, 2018). Além disso, tem investido em acordos com grandes marcas para o desenvolvimento de conteúdo exclusivo, como a parceria com a Disney Digital Network, anunciada em janeiro de 2018. Pelo acordo, os quatro maiores criadores da plataforma (Jacksepticeye, LuzuGames, Markiplier e 
Strawburry 17) farão transmissões sobre conteúdos exclusivos criados sob demanda (ALVES, 2018).

A Twitch tem como estratégia focar nos streamers que geram maior audiência, seguindo a mesma lógica mercadológica de outras plataformas como YouTube e Facebook. O algoritmo de recomendação é responsável por garantir que jogos e canais mais populares sejam constantemente recomendados aos usuários, fazendo com que uma pequena parcela das transmissões, algo em torno de 10\%, concentrem 95\% da audiência (PAZ; MONTARDO, 2018 in KAYTOUE et al., 2012).

A Twitch se destaca dos demais serviços de streaming principalmente por essa capacidade de movimentar negócios no mercado de games e de tecnologia, aliado ao seu pioneirismo no cenário e sua popularidade entre os principais produtores de conteúdos (MONTARDO et al., 2017). A plataforma é, ao mesmo tempo, responsável e consequência de um processo de midiatização e espetacularização dos games. Esse fenômeno parece ser mais complexo e muito mais profundo do que apenas o resultado de uma plataforma digital, necessitando ser observado sob a ótica de transformações estruturais na sociedade contemporânea.

\section{Midiatização dos games}

O conceito de midiatização faz uso de diversas teorias e metodologias que fornecem um arcabouço para a análise e compreensão sobre o papel mutável dos meios de comunicação na relação com os demais processos culturais e sociais (Hjarvard, 2014). Dessa forma, a midiatização evidencia-se como opção adequada para analisar a transformação dos processos comunicacionais dos games, tema fundamentalmente interdisciplinar que atrai estudos de diversas áreas de conhecimento, como filosofia, semiótica, psicologia, antropologia, comunicação e tecnologia. Quando o assunto é games, "tem-se aí, de fato, um campo híbrido, poli e metamórfico" (SANTAELLA, 2014, p. 221).

O processo de midiatização pode apresentar duas formas distintas, porém não excludentes, que frequentemente atuam de maneira combinada: a midiatização direta (forte) e a indireta (fraca) (HJARVARD, 2014). A midiatização direta se dá quando uma determinada ação social até então realizada a partir de interação face a face passa a ser realizada através de um determinado dispositivo tecnológico. Stig Hjarvard, em A midiatização da cultura de massa, cita o jogo de xadrez para ilustrar seu conceito de midiatização direta, quando o tabuleiro físico se transforma em um simulador de computador. Neste caso, é fácil reconhecer o "antes" 
e o "depois" do processo de midiatização. As regras, objetivos e estruturas do jogo se mantêm, porém o uso de um computador abre novas possibilidades de exploração do jogo de forma assíncrona, à distância, inclusive de maneira individual, jogando-se apenas contra a máquina.

No entanto, se pensarmos no processo de streaming dos games, podemos defini-lo também com um exemplo de midiatização indireta (fraca). Os jogos em videogames sempre foram realizados por meio de dispositivos eletrônicos, mas ao longo dos últimos anos o processo de jogar foi transformado de um ato individual ou restrito a pequenos grupos localizados fisicamente próximos (por exemplo, em lan houses), para uma experiência global, transmitida e compartilhada por todo o planeta de forma simultânea e interativa, sendo diretamente influenciada pelo meio (plataformas de streaming) e por outros sujeitos (gamers e viewers).

Esse processo de midiatização indireta se dá de forma mais sutil, mas nem por isso menos transformadora do que o caso do simulador de xadrez. Em ambos os casos a midiatização diz respeito a uma crescente dependência das instituições por recursos controlados pelos meios de comunicação.

A midiatização concentra-se nas transformações estruturais que os meios de comunicação impõem à cultura, podendo ser compreendida como uma característica intrínseca das sociedades contemporâneas, que possibilita aos sujeitos transitarem entre produção e consumo dos produtos midiáticos (HJARVARD, 2014).

Torna-se importante um pequeno adendo para resgatar o conceito de mediação dos processos de comunicação - focado nos efeitos da comunicação localizados em tempo e espaço específicos - para diferenciá-los do processo de midiatização, que está interessado nas transformações estruturais de longo prazo das relações entre mídia, cultura e sociedade. Ou seja, a midiatização diz respeito à institucionalização de novos padrões de interações, bem como à maneira como se dão as relações sociais entre os sujeitos.

A popularização da internet de banda larga e o fácil acesso às ferramentas de autoria permitem que os usuários possam criar e compartilhar seus próprios conteúdos midiáticos, levando os serviços prestados pelos veículos de comunicação a passarem para uma lógica mercadológica bilateral, onde de um lado está o profissionalismo ofertado pela mídia, e do outro, o envolvimento do público/usuário (HJARVARD, 2014). Evidencia-se assim que a midiatização não diz respeito apenas ao resultado de transformações internas dos meios de comunicação, mas é também produto de um complexo conjunto de mudanças tecnológicas, políticas e econômicas. 
Do jogo ao espetáculo

Há menos de duas décadas, o ato de jogar videogames tratava-se em geral de um evento particular, realizado de forma individual ou ainda com poucas pessoas, amigos e familiares que se reuniam em volta de um monitor de TV para participar e/ou acompanhar algumas partidas (salvo exceções, como campeonatos ou espaços como fliperamas). Neste contexto, simultaneamente ao fim da partida, terminava também a experiência do jogo. Isso mudou radicalmente nos últimos anos.

O fácil acesso a dispositivos de gravação, edição e compartilhamento de conteúdo transformou a brincadeira em um evento público e mercadológico, que pode ser acompanhado por milhares de pessoas a partir de qualquer parte do mundo, de forma síncrona ou assíncrona. O streaming popularizou novas formas de compartilhar a experiência de jogo, seja por meio de resenhas, transmissão de partidas amadoras, campeonatos internacionais, tutorais ou dicas de jogos, entre outros. São experiências que abrem uma gama de observações a respeito das lógicas de midiatização e da espetacularização dos games.

Guy Debord ${ }^{5}, 2003$, destaca que a representação imagética, na sociedade do espetáculo, está separada da experiência real e concreta, de forma que tudo se torna uma representação. Ao atualizar a concepção marxista do capitalismo, o autor afirma que a sociedade continua a ser baseada no acúmulo de mercadorias, mas que essas já não seriam mais apenas fruto da produção industrial, mas sim de uma sociedade baseada na produção e consumo de imagens. Em suma, “o espetáculo não é um conjunto de imagens, mas uma relação social entre pessoas, mediada por imagens" (DEBORD, 2003, p. 14).

$\mathrm{Na}$ sociedade do espetáculo, a separação entre as experiências concretas e a representação imagética destas experiências nos levam à perda do controle sobre a dimensão simbólica, onde as experiências concretas são esvaziadas de sentido e passam a ser também fetichizadas.

Durante uma transmissão, o streamer permite capturar, para então exibir, suas expressões faciais, além de simular um diálogo com sua audiência, que pode acontecer por meio de chats e conversas por voz. Mais de que jogar, streaming no jogo implica em assumir certas características performáticas encenadas nas quais as ações do streamer buscam agradar e fidelizar a audiência (AGUIAR, 2018).

\footnotetext{
${ }^{5}$ Guy Debord (1931-1994) foi um pensador, cineasta e ativista francês. Foi um dos fundadores da Internacional Situacionista, movimento político e artístico bastante ativo no final dos anos 60 .
} 
No contexto de jogo, o conceito de performance extrapola os atributos de desempenho técnicos e ganha contorno de caráter social e performático. O jogador, ou no caso o streamer, interpreta um papel durante a transmissão, quando sua habilidade técnica é tão ou mais relevante que sua capacidade de entreter e cativar a audiência. Para tal, esses streamers acabam, em grande parte, optando por seguir modelos e formatos de transmissões realizados por outros canais bem-sucedidos, abrindo mão de uma suposta autenticidade para promover seu conteúdo. Nesse sentido, "a exterioridade do espetáculo em relação ao homem que age aparece nisto, os seus próprios gestos já não são seus, mas de um outro que lhes apresenta" (DEBORD, 2003, p. $14)$.

A maneira como o streamer vivencia a experiência do jogo está diretamente influenciada pela noção de que sua performance está sendo acompanhada pelo público, acrescentando uma camada de expectativas quanto ao seu desempenho, humor, aparência e capacidade de interação com os demais jogadores (no caso das partidas multiplayer) e do próprio público, o que por sua vez retroalimenta o streamer com seu feedback síncrono e assíncrono por meio de chat de texto e voz, emoticons, stickres e diferentes linguagens através de redes sociais conectadas. Forma-se, assim, um novo processo de comunicação baseado no compartilhamento da experiência midiatizada do jogo.

Interessante ainda observar que esse processo de comunicação não se encerra necessariamente quando uma partida termina. Dada a própria dinâmica comunicacional nos contextos digitais, essas interações transcendem o espaço-tempo da transmissão e continuam, por vezes, a reverberar em outros contextos comunicacionais.

Não é sem razão, portanto, que um elemento constantemente utilizado por streamers em suas páginas da Twitch é a integração para divulgação em outras redes sociais, que proporcionem melhor conectividade social e engajamento com o público (SJÖBLOM et al., 2019). Essas redes costumam ser utilizadas para promover as transmissões e gerar aumento de audiência. 


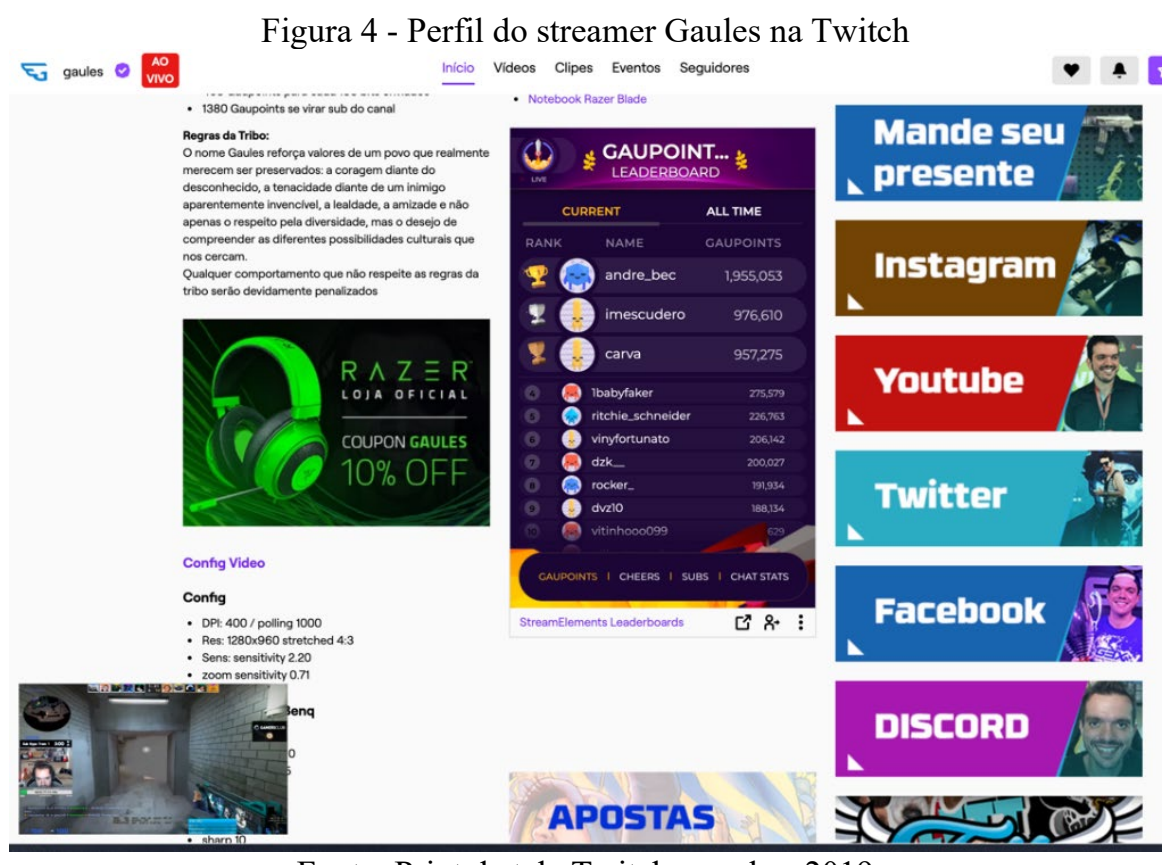

Fonte: Print de tela Twitch - gaules, 2019

A Figura 4 refere-se ao perfil do streamer Gaules na plataforma Twitch, que ilustra o espaço para divulgação e integração com redes sociais digitais como o Instagram, YouTube, Twitter, Facebook e Discord. Essa conectividade tem grande importância para a construção e fortalecimento de uma comunidade centralizada na figura do streamer, que passa a ter o status de digital influencer, podendo utilizar-se do público enquanto mercadoria em transações comerciais dentro e fora da plataforma (SJÖBLOM et al., 2019).

Enquanto teoria de "meio termo", a midiatização propõe a análise focada predominantemente no nível intermediário "dos arranjos sociais e culturais específicos, isto é, o nível de instituições sociais (política e religião) e de fenômenos culturais (brincadeiras infantis) específicos no âmbito de um dado contexto histórico e sociogeográfíco" (HJARVARD, 2014, p. 17). Portanto, diz respeito a uma abordagem institucional que permite fazer generalizações entre indivíduos e determinados setores da sociedade. Compreender a identidade desses indivíduos, sua cultura específica e os contextos nos quais estão inseridos é fundamental para analisar o papel mutável da mídia na sociedade contemporânea.

O processo de midiatização indireta pelo qual o streaming de games se constitui leva o espectador ao exercício de uma interação mediada, através da qual, mais do que assistir, ele participa, comenta e é coprodutor do conteúdo ou da experiência de jogo. Afinal, como acentua HJARVARD (2014, p. 52), "interação social consiste em comunicação e ação". Esse elevado grau de interação aliado ao avanço da tecnologia tornou os meios de comunicação parte da vida cotidiana, de forma que os conteúdos consumidos online e as interações entre os indivíduos na 
rede são parte do processo de construção da identidade desses sujeitos. Em suas transmissões, os streamers possuem alcance global e afetam milhares de pessoas todos os dias, transformando o contexto cultural no qual estão envolvidos e contribuindo para a construção da identidade gamer.

Em linhas gerais, identidade diz respeito à construção de significados, conjuntos de atributos culturais inter-relacionados que prevalecem sobre outras fontes de significado (CASTELLS, 2018). No contexto dos games, fala-se em uma identidade gamer, formada por uma gama de culturas e subculturas que constroem determinado sujeito:

Aquilo que hoje é chamado de "cultura gamer" é, de fato, bastante intrincado, uma área de produção criativa, de atividade e de teorizações que se transforma a uma velocidade surpreendente, não se deixando agarrar em categorias e classificações fixas, pois games são movidos pela inovação tecnológica que assume a vanguarda em relação a todas as outras mídias digitais (SANTAELLA, 2013, p. 221)

Foi, então, graças à permanente inovação tecnológica que o ato de jogar uma partida de game se transformou em espetáculo, pois incluiu um ingrediente sem o qual o espetáculo não existe - o público. Em geral, o streaming não transporta apenas as cenas da disputa, mas também apresenta na tela a face pública do competidor, que combina cenários, esboça reações e interage com os viewers de forma multimidiática. A estratégia equivale a dizer que "os streamers não apenas jogam um jogo e o transmitem, porém jogam 'para' e 'com' a sua audiência" (SEULA; AMARO, 2018).

Dessa forma, quando o gamer assume o papel social de streamer, diferentes competências lhes são exigidas, iniciando-se assim uma ação de interação direta com outros sujeitos que podem ser também gamers, streamers ou viewers, cada um contribuindo e modificando o andamento do jogo, de forma a produzir uma simbiose de experiência midiatizada e espetacularizada de jogos online.

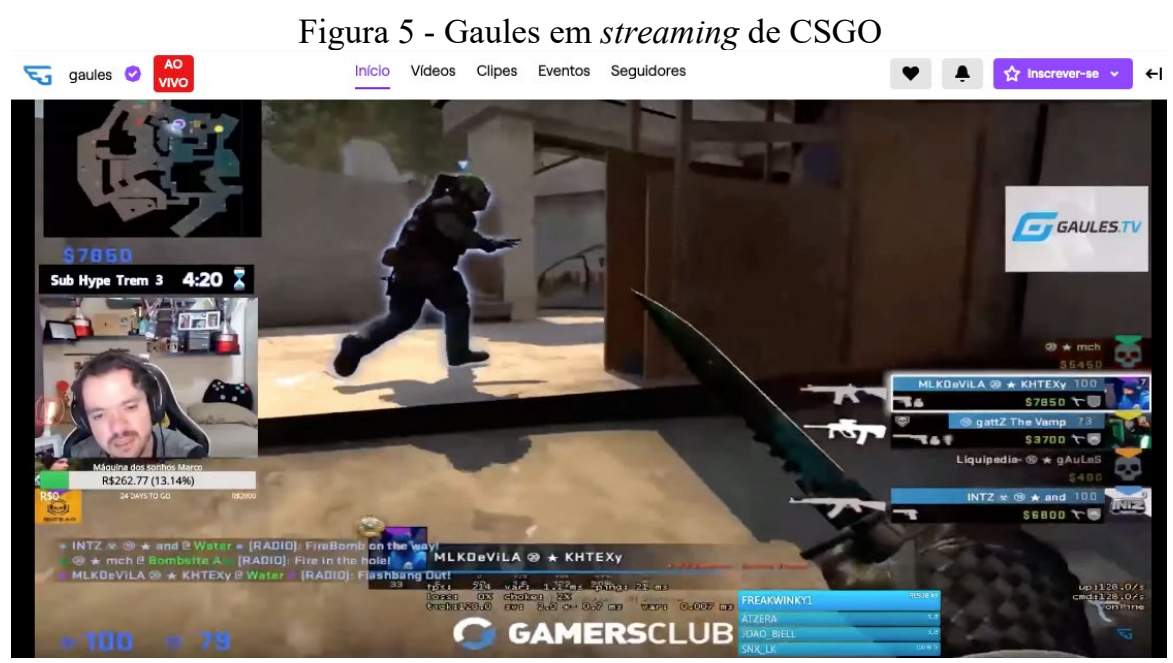

Fonte: Print de tela Twitch - gaules, 2019 
$\mathrm{Na}$ Figura 5, vemos o aspecto performativo na conduta da narrativa por parte da streamer, com frases como "queria jogar agressivo, mas vai dar merda, mano", ou ainda “quebramos, guys", como uma alusão à sua má performance durante a partida, explicando-se à audiência e aos demais jogadores a respeito de seu desempenho. Esses aspectos somam-se à construção de uma identidade que contempla o cenário ao fundo, a vestimenta, o vocabulário e demais artifícios para conquistar o carisma das audiências. Como comentamos acima, a sobreposição da voz do streamer ao som do jogo é também um indicativo da predominância da identidade sobre a interação do game em si.

Tais fatores favorecem a celebração do streamer como uma figura pública e influente, além de deixar mais evidente o processo de midiatização indireta aqui descrito.

\section{Considerações finais}

A perspectiva da midiatização associada ao conceito de sociedade do espetáculo permitiu um aporte possível para apreender, ao menos no atual estágio do desenvolvimento tecnológico, a complexa rede de relações e interações que se instala no processo de streaming de games. Nota-se que o processo de midiatização evidente dos games culminou com a popularização das transmissões de partidas, processo no qual mídia, atores e público atuam como parceiros na produção de conteúdo midiático para consumo no mercado global de entretenimento.

Ao analisar o comportamento dos gamers na plataforma Twitch, observamos que diferentes papéis são dados a eles, o que torna a representação em torno dos jogos mais complexa e multifacetada. Gamers, streamers e viewers se sobrepõem em atividades de interação que espetacularizam o jogador que se apresenta via streaming, criando um cenário perfeito ao de surgimento de celebridades ou influencers, próprios de outros tipos de mídia.

Por fim, observa-se ainda que, cada vez mais, as instituições e o público dependem dos meios de comunicação e da tecnologia para mediar as interações sociais, que sofrem constantes adequações e novos arranjos estruturais. No caso dos games, essa dependência, que aumenta com a midiatização indireta, tem impactos diretos no crescimento da indústria e empregos, no aumento da diversidade dos públicos, nos interesses dos patrocinadores e em outros elementos aqui apontados. 


\section{Referências}

AGUIAR, B. C. A figura híbrida do streamer de jogos: Oscilando entre autenticidade e performance. II Seminário Internacional de Pesquisas em Midiatização e Processos Sociais, São Leopoldo. Anais... São Leopoldo: Unisinos, v. 1, 2, p. 6, 2018.

ALVES, S. Twitch e Disney fecham parceria para produção de conteúdo exclusivo. B9, 18 jan. 2018. Disponível em: <https://www.b9.com.br/85128/twitch-e-disney-fecham-parceriapara-producao-de-conteudo-exclusivo/>. Acesso em: 26 nov. 2019.

AMAZON.com to Acquire Twitch. Business Wire, 2014. Disponível em:

$<$ https://www.businesswire.com/news/home/20140825005820/en/Amazon.com-AcquireTwitch>. Acesso em: 25 nov. 2019.

CASSELL, J.; JENKINS, H. From Barbie to Mortal Kombat: gender and computer games. 1. ed. Cambridge, Mass.: MIT Press, 1998. Disponível em:

$<$ https://archive.org/details/frombarbietomort00cass\#maincontent>. Acesso em: 10 mai. 2020.

CASTELlS, M. O Poder da Identidade. 1. ed. São Paulo: Paz \& Terra, 2018.

CISCO Visual Networking Index: Forecast and Trends, 2017-2022. Portal Cisco. 2018. Disponível em: <https://www.cisco.com/c/en/us/solutions/collateral/service-provider/visualnetworking-index-vni/white-paper-c11-741490.html>. Acesso em: 9 fev. 2019.

DALL'AGNESE, C. T. W.; BARRICHELLO, E. M. M. R. Por uma abordagem ecológica e contextual da comunicação em tempos de midiatização profunda. Culturas Midiáticas, v. 11, n. 1, 2018. Disponível em:

$<$ http://www.periodicos.ufpb.br/ojs2/index.php/cm/article/view/40708>. Acesso em: 9 fev. 2019.

DEBORD, G. A Sociedade do Espetáculo. Cascais: Coletivo Periferia, 2003. Disponível em: $<$ https://www.marxists.org/portugues/debord/1967/11/sociedade.pdf $>$. Acesso em: 9 fev. 2019.

GAMING video content (GVC) 2017. SuperData Research, 2017. Disponível em: $<$ https://www.superdataresearch.com/market-data/gaming-video-content/>. Acesso em: 25 nov. 2018.

GOULAR, L. A.; NARDI, H. C. Jogos digitais, identidade e identificação não-masculina / não-heterossexual. Revista Estudos Feministas, v. 25, n. 1, 2017.

HEPP, A. As configurações comunicativas de mundos midiatizados: pesquisa da midiatização na era da "mediação de tudo". MATRIZes, v. 8, n. 1, p. 45-64, 2014.

HICKS, A. Streamlabs Livestreaming Q4 Report: Tipping reaches \$100M for the year; YouTube Dominates in Streamer Growth, increasing by 343\% as Twitch rises 197\% in 2017. Streamlabs, 25 jan. 2018. Disponível em: <https://blog.streamlabs.com/streamlabslivestreaming-q4-report-tipping-reaches-100m-for-the-year-youtube-dominates-in4bf450fae536>. Acesso em: 9 fev. 2019. 
HJARVARD, S. A Midiatização da Cultura e da Sociedade. 1. ed. São Leopoldo: Unisinos, 2014.

JUNTANDO-se ao Programa de afiliados. Twitch.tv. 2018. Disponível em:

$<$ https://help.twitch.tv/customer/pt_br/portal/articles/2785927-juntando-se-ao-programa-deafiliados\#access>. Acesso em: 25 nov. 2019.

KARHAWI, I. Influenciadores digitais: conceitos e práticas em discussão. Communicare, v. Volume 17 - Edição especial de 70 anos da Faculdade Cásper Líbero, n. 17, p. 15, 2017.

KOWAL, M. et al. Different cognitive abilities displayed by action video gamers and nongamers. Computers in Human Behavior, v. 88, p. 255-262, 2018.

MCGONIGAL, J. A realidade em jogo. Editora Best Seller, 2017.

MONTARDO, S. et al. Consumo digital como performance sociotécnica: Análise dos usos da plataforma de streaming de games Twitch. Comunicação Mídia e Consumo, v. 14, n. 40, p. 45-67, 2017.

NEWZOO. Newzoo Global Games Market Report 2018 | Light Version. Newzoo, 2018. Disponível em: <https://newzoo.com/insights/trend-reports/newzoo-global-games-marketreport-2018-light-version/> . Acesso em: 16 set. 2019.

NEWZOO. Global Esports Market Report 2019 - Light Version. Newzoo, 2019a. Disponível em:

$<$ https://resources.newzoo.com/hubfs/Reports/2019_Free_Global_Esports_Market_Report.pd f>. Acesso em: 16 set. 2019.

NEWZOO. Insights Into Latin America's Esports Fans. Newzoo, 2019b. Disponível em: $<$ https://www.the-esports-bar.com/content/dam/sitebuilder/rm/esportsbar/pdf/Esports_Business_in_LATAM.pdf>. Acesso em: 10 set. 2019.

OLIVEIRA, L. P. et al. Restrições de Stream de Vídeo no Brasil. Conexões - Ciência e Tecnologia, v. 11, n. 3, p. 113-119, 2017.

PAAßEN, B.; MORGENROTH, T.; STRATEMEYER, M. What is a True Gamer? The Male Gamer Stereotype and the Marginalization of Women in Video Game Culture. Sex Roles, v. 76, n. 7, p. 421-435, 2017.

PAZ, S.; MONTARDO, S. P. Performance play: consumo digital como performance no streaming de games da plataforma Twitch. Fronteiras - estudos midiáticos, v. 20, n. 2, p. 190-203-203, 2018.

PESQUISA Game Brasil 2019. Sioux Group, 2019. Disponível em: $<$ https://www.pesquisagamebrasil.com.br/>. Acesso em: 23 set. 2019.

SANTAELLA, L. Comunicação ubíqua: Repercussões na cultura e na educação. 1a Edição ed. São Paulo: Editora Paulus, 2013.

SEULA, R. S.; AMARO, M. Procedimentos para análise de performance de streamers de games. XVII SIMPÓSIO BRASILEIRO DE JOGOS E ENTRETENIMENTO DIGITAL, Foz do Iguaçu. Anais... Foz do Iguaçu: PUC-PR, p. 7, 2018. 
SILVA, M. P.; TAVARES, D. C. O espetáculo midiático contemporâneo na construção social. Culturas Midiáticas, v. 6, n. 1, 2013. Disponível em:

$<\mathrm{http}$ //www.periodicos.ufpb.br/index.php/cm/article/view/16200>. Acesso em: 9 fev. 2019.

SJÖBLOM, M. et al. The ingredients of Twitch streaming: Affordances of game streams. Computers in Human Behavior, v. 92, p. 20-28, 2019.

TIC Domicílios 2018. CETIC.BR, Centro Regional de Estudos para o Desenvolvimento da Sociedade da Informação. 2019. Disponível em: <http://www.cetic.br/portaldedados/>. Acesso em: 29 set. 2019.

ZICHERMANN, G.; CUNNINGHAM, C. Gamification by Design: Implementing Game Mechanics in Web and Mobile Apps. O'Reilly Media, Inc., 2011.

\footnotetext{
${ }^{a}$ Mestre em Linguagens, Mídia e Arte pela PUC-Campinas, Brasil. Bacharel em Publicidade e Propaganda pela Universidade Paulista.

${ }^{\mathrm{b}}$ Professor pesquisador da Pontifícia Universidade Católica de Campinas, Brasil. Docente do mestrado em Linguagens, Mídia e Arte. Doutor em Artes Visuais pela Universidade Estadual de Campinas, com estágio no departamento de Estudos Culturais, Goldsmiths College, Universidade de Londres.

${ }^{\mathrm{c}}$ Jornalista, professor e pesquisador. Docente do mestrado interdisciplinar em Linguagens, Mídia e Arte e da Faculdade de Jornalismo na PUC-Campinas, Brasil. Doutor em Ciências da Comunicação pela Escola de Comunicações e Artes (ECA-USP).
} 